\title{
ABLATION AND CHEMICAL ALTERATION OF COSMIC DUST PARTICLES DURING ENTRY INTO THE
} EARTH'S ATMOSPHERE

\author{
N. G. Rudraswami ${ }^{1}$, M. Shyam Prasad ${ }^{1}$, S. Dey ${ }^{1,2}$, J. M. C. Plane ${ }^{3}$, W. Feng ${ }^{3,4}$, J. D. Carrillo-Sánchez ${ }^{3}$, and \\ D. FERNANDES ${ }^{1}$ \\ ${ }^{1}$ National Institute of Oceanography (Council of Scientific and Industrial Research), Dona Paula, Goa 403004, India; rudra@nio.org \\ ${ }^{2}$ Indian Institute of Technology, Roorkee, Uttarakhand 247667, India \\ ${ }^{3}$ School of Chemistry, University of Leeds, Leeds LS2 9JT, UK \\ ${ }^{4}$ NCAS, School of Earth and Environment, University of Leeds, Leeds, LS2 9JT, UK \\ Received 2016 September 11; revised 2016 October 28; accepted 2016 November 5; published 2016 December 2
}

\begin{abstract}
Most dust-sized cosmic particles undergo ablation and chemical alteration during atmospheric entry, which alters their original properties. A comprehensive understanding of this process is essential in order to decipher their preentry characteristics. The purpose of the study is to illustrate the process of vaporization of different elements for various entry parameters. The numerical results for particles of various sizes and various zenith angles are treated in order to understand the changes in chemical composition that the particles undergo as they enter the atmosphere. Particles with large sizes ( $>$ few hundred $\mu \mathrm{m}$ ) and high entry velocities $\left(>16 \mathrm{~km} \mathrm{~s}^{-1}\right.$ ) experience less time at peak temperatures compared to those that have lower velocities. Model calculations suggest that particles can survive with an entry velocity of $11 \mathrm{~km} \mathrm{~s}^{-1}$ and zenith angles (ZA) of $30^{\circ}-90^{\circ}$, which accounts for $\sim 66 \%$ of the region where particles retain their identities. Our results suggest that the changes in chemical composition of $\mathrm{MgO}, \mathrm{SiO}_{2}$, and $\mathrm{FeO}$ are not significant for an entry velocity of $11 \mathrm{~km} \mathrm{~s}^{-1}$ and sizes $<300 \mu \mathrm{m}$, but the changes in these compositions become significant beyond this size, where $\mathrm{FeO}$ is lost to a major extent. However, at $16 \mathrm{~km} \mathrm{~s}^{-1}$ the changes in $\mathrm{MgO}, \mathrm{SiO}_{2}$, and $\mathrm{FeO}$ are very intense, which is also reflected in $\mathrm{Mg} / \mathrm{Si}$, $\mathrm{Fe} / \mathrm{Si}, \mathrm{Ca} / \mathrm{Si}$, and $\mathrm{Al} / \mathrm{Si}$ ratios, even for particles with a size of $100 \mu \mathrm{m}$. Beyond $400 \mu \mathrm{m}$ particle sizes at $16 \mathrm{~km} \mathrm{~s}^{-1}$, most of the major elements are vaporized, leaving the refractory elements, $\mathrm{Al}$ and $\mathrm{Ca}$, suspended in the troposphere.
\end{abstract}

Key words: atmospheric effects - Earth - interplanetary medium - minor planets, asteroids: general - Sun: general

\section{INTRODUCTION}

Earth is continuously bombarded by high-speed particles from both incoming asteroidal and cometary material. Although efforts have been made to learn the exact contributions from each of these sources, such efforts are nevertheless hampered by large levels of uncertainties (e.g., Plane 2012). Micrometeorites are the largest contributors of extra-terrestrial material; this material is recovered from the Earth's surface using different collection techniques that target the stratosphere, Antarctica, and deep-sea sediments (Love \& Brownlee 1993; Taylor et al. 1998; Peucker-Ehrenbrink \& Ravizza 2000; Plane 2012; Prasad et al. 2013). The micrometeorites found on the Earth's surface have distinct chemical compositions that show similarities and differences with respect to the precursors they originate from; however, in general, a large number of micrometeorites are related to carbonaceous chondrites (e.g., Kurat et al. 1994; Brownlee et al. 1997; Taylor et al. 2000, 2012; Yada et al. 2005; Rudraswami et al. 2011, 2012, 2014, 2015a, 2015b, 2016a). The deviations in the chemical compositions from the precursors are caused by modification that occurs during melting and vaporization that take place as these particles enter into the Earth's atmosphere. These modifications are dominated by a loss of elements based on their relative volatilities, and other physical processes that are parameterized by key variables such as size, density, entry velocity, and angle of entry, in addition to others (Love \& Brownlee 1991; Rudraswami et al. 2015a, 2016a). The origin of micrometeorites is currently debated, whether the micrometeorites are asteroidal or cometary, and to what extent the origin contributes to the micrometeorites' flux is also debated (Dermott et al. 1994; Brownlee 2001; Nesvorný et al. 2010, 2011). The other potential source that has been suggested is fragmentation of large objects that hit the atmosphere (Lal \& Jull 2002). This has not been supported by micrometeorite chemical analyses, which are inclined toward the major contributor being carbonaceous chondrites, whereas a majority of meteorites are from ordinary chondrites (Krot et al. 2003; Taylor et al. 2007). In addition, large cosmic spherules such as glass spherules do not entirely support the concept of fragmentation (Rudraswami et al. 2012). Moreover, the air pressure at the altitude above Earth's surface, where ablation and vaporization occur, is very low, which allows meteoritic material to fragment into such small particles, even in material with small tensile strength. Nevertheless, the explanation that a combination of asteroidal and cometary materials contributes to micrometeorite flux appears to be more plausible. Cometary bodies have the best preserved solar system materials (Brownlee et al. 2006; Brownlee 2014). Getting hold of these materials that have not altered during atmospheric entry will enable us to provide an understanding of the diverse origins of these enigmatic particles in the solar nebula and provide insights into their origins. Micrometeorites' interactions with the Earth's atmosphere can be constrained properly by understanding the process of chemical composition as the micrometeorites enter at different altitudes under different conditions. Earlier model calculations largely focused on the deceleration of particles at various entry velocities, thereby estimating the ablation and temperature that the particles undergo at various sizes and entry angles (Flynn 1989a, 1989b; 
Love \& Brownlee 1993; Brownlee 2001; Kortenkamp et al. 2001). Our understanding of the role of elemental ablation will allow us to identify the chemical alterations experienced by the particles. In doing so, the properties of the particles before their entry can be inferred. This may possibly lead us to infer the type of precursors these particles belong to, though this will not be as easy as it seems because it will involve the association of multiple parameters that will behave similarly under different entry velocities, zenith angles, and sizes. We review our understanding of the various physical and chemical properties related to these particles; these properties are important for understanding how these particles are modified from their original identities. The change in chemical composition during entry depends on various parameters (entry velocity, mass, density, zenith angle (ZA), and chemical composition) of entering particles. The compositional variation during entry and the elemental volatility control the bulk chemical composition and hence bulk chemical composition alone is inadequate to resolve our understanding of precursors.

Numerical calculations are significant for quantifying the interactions that lead to chemical and physical modifications during atmospheric entry. Numerical calculations will also be a useful parameter for providing estimates of the flux, which has so far been assessed with multiple values (Taylor et al. 1998; Yada et al. 2004; Plane 2012; Prasad et al. 2013). We use the Chemical ABlation MODel (CABMOD; Vondrak et al. 2008) to derive the ablation rate profiles of the most abundant elements as a function of the altitude for each meteoroid with a given mass, velocity, and entry angle after it enters the atmosphere. The present study focuses on understanding the physical modification associated with chemical alteration that incoming particles undergo during entry; this modification provides us with the probability of associating a particle with its predecessor. Comparison of elemental properties of micrometeorites of different sizes, entry velocities, and ZAs has revealed a number of interesting aspects of particles undergoing atmospheric entry that will be discussed in this study.

\section{MODEL DETAILS}

The CABMOD model includes the standard treatment of meteor physics: a balance of frictional heating by radiative losses and the absorption of heat energy through temperature increase, melting, phase transitions, and vaporization. (Vondrak et al. 2008; Plane 2012). The model considers the nonthermal sputtering mass-loss of particles due to inelastic collisions with air molecules before melt, followed by ionization of ablated particles, diffusion-controlled ablation of alkali metals, and Langmuir evaporation of metal atoms and oxides from molten bulk using the MAGMA chemical equilibrium code (Schaefer \& Fegley 2005). The classical theory of interaction with the atmosphere treats a particle as a homogeneous sphere where heat transfer is isothermal (Vondrak et al. 2008). The emissivity considered in this study is set to 1 . The emission efficiency declines when the particle size is analogous or less than the radiation wavelength (Bohren \& Huffman 1983, p. 130). Earlier, Vondrak et al. (2008) took an estimate that took into account the atmospheric curvature for input particles with a high zenith angle and established that this effect is not significant. The gravity is included in Equation (1) of Vondrak et al. (2008) and its effect is seen to be insignificant in the range of velocities considered here for particle entry.
CABMOD integrates in terms of height, so it is capable of estimating the elemental deposition of different metals using MAGMA. Additional comprehensive processes related to the chemical ablation of particles for various entry parameters is given in Vondrak et al. (2008). The particle initial composition is preferred to be a CI chondritic composition that is mainly composed of olivine. The behavior of the olivine phases diagram (Figure 4(a) of Vondrak et al. 2008) suggests that the $\mathrm{Fe} / \mathrm{Mg}$ ratio 0.8 starts to melt at $1730 \mathrm{~K}$ and becomes completely melted at $1800 \mathrm{~K}$, which is considered to be the melting point of the particle. The CABMOD model includes a sigmoid temperature curve that is an empirical function that describes the depletion of the elements in a more realistic way. It should be noted that the term ablation covers both sputtering and vaporization from the molten bulk. During the ablation process, the primary composition changes to secondary composition, leading a loss of the original properties. To achieve a good computational accuracy, the integration is sampled with a vertical height resolution of $100 \mathrm{~m}$. The ablation or temperature change is insignificant within vertical resolutions smaller than $100 \mathrm{~m}$ for any size particle, except for large entry velocities $\left(>16 \mathrm{~km} \mathrm{~s}^{-1}\right)$, where the change starts to become relevant. Our goal is to provide an overall demonstration of the particle response during atmospheric entry. The general approach of simulations during the last few decades has primarily relied on understanding the changes to the entry parameters, and thus their ramifications for the physical properties of particles, such as size and the percentage of ablation. In our study we have made an effort to identify the variation in the elemental composition associated with ablation for various entry phenomena. We have restricted the entry velocity to $16 \mathrm{~km} \mathrm{~s}^{-1}$ because increasing entry velocity beyond this point and working with particle sizes of $100-700 \mu \mathrm{m}$ results in an ablation of $>90 \%$, which is futile. Particles that enter the Earth's atmosphere with greater velocities will undergo large ablation due to frictional heating from striking air molecules and will lose their identities as particles. The main stream of particles that hits the upper atmosphere at $\leqslant 16 \mathrm{~km} \mathrm{~s}^{-1}$ should survive the atmospheric entry, and should continue being micrometeorites (Nesvorný et al. 2011; CarrilloSánchez et al. 2015). Flynn (1989a, 1989b) used densities of $\sim 1 \mathrm{~g} \mathrm{~cm}^{-3}$, which are from fluffy materials whose main sources are cometary bodies. However, further detailed micrometeorite modeling by Love \& Brownlee (1991) that used various entry velocities and ZAs considered a particle density of $\sim 3 \mathrm{~g} \mathrm{~cm}^{-3}$. The measured density of stratospheric interplanetary dust particles is dominated by particles that are $\sim 2 \mathrm{~g} \mathrm{~cm}^{-3}$, which is consistent with those found in CI-chondrites (Love et al. 1994). The present study considers the chemical compositions and properties of entering particles that are similar to primitive CI chondritic compositions with a density of $\sim 2 \mathrm{~g} \mathrm{~cm}^{-3}$ (Mason 1971; Sears \& Dodd 1988, pp. 3-31; Lodders \& Fegley 1998). The major elemental composition of micrometeorites conforms to a CI composition, as suggested by various studies (e.g., Brownlee et al. 1997; Taylor et al. 2000; Prasad et al. 2013). The majority of the dust producers in the asteroid belt are bodies that have low tensile strength and that can fragment into smaller particles during collisions; CI chondrite fits this category very well. During collisions between two asteroids, properties such as low density and high porosity can be useful for facilitating a breakdown into dust particles in the size ranges that define micrometeorites. 

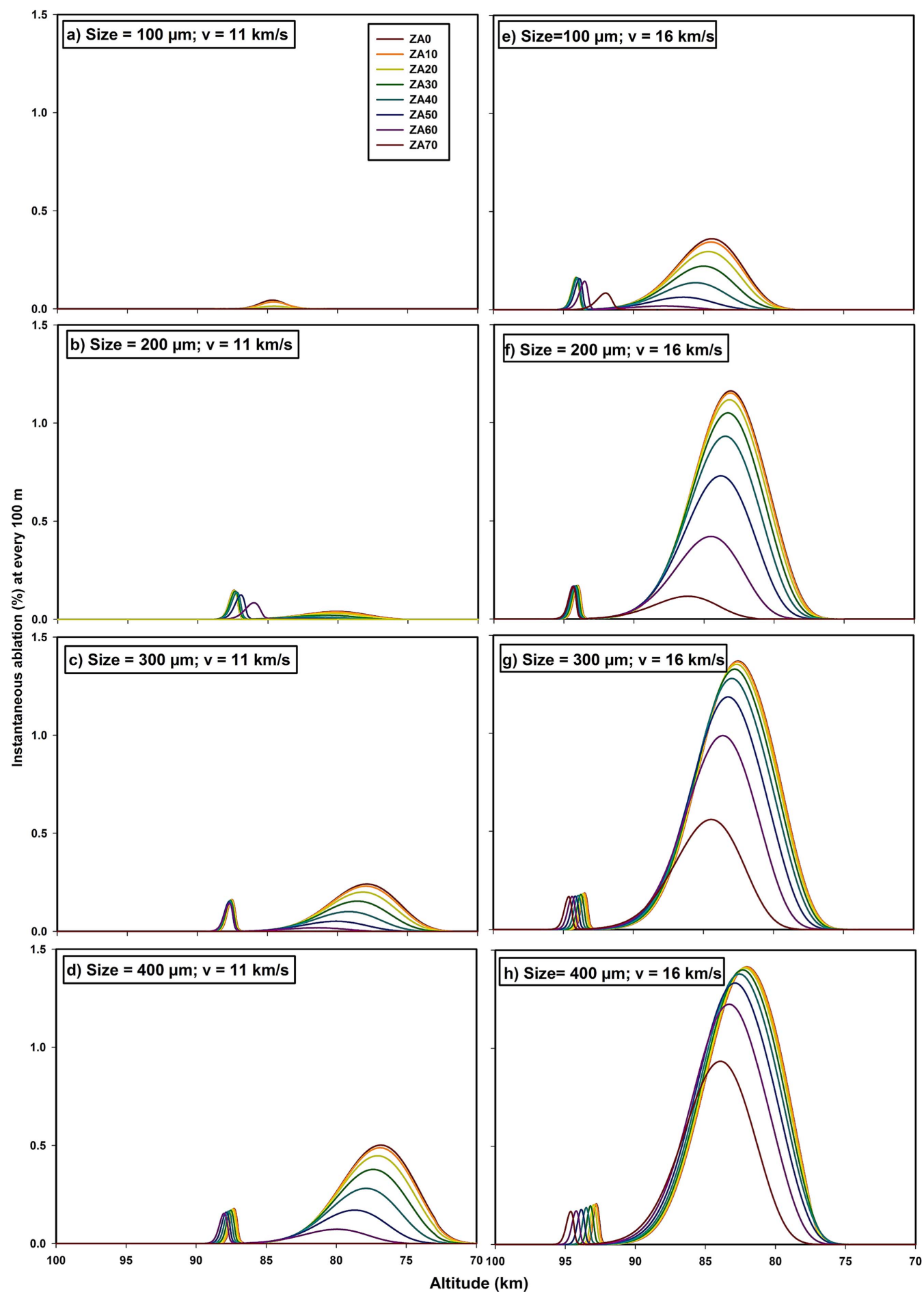

Figure 1. The representative instantaneous ablation (\%) of the particle for every $100 \mathrm{~m}$ at various altitudes and sizes from 100 to $400 \mu \mathrm{m}$ for various ZAs with entry velocities of $11 \mathrm{~km} \mathrm{~s}^{-1}(\mathrm{a}-\mathrm{d})$ and $16 \mathrm{~km} \mathrm{~s}^{-1}(\mathrm{e}-\mathrm{h})$. The first peak is for the volatile element (Na and K), followed by ablation of major elements. The ZAs $80^{\circ}$ and $90^{\circ}$ for both entry velocities ( 11 and $16 \mathrm{~km} \mathrm{~s}^{-1}$ ) are not included, as the instantaneous ablation percent is insignificant.

Conversely, researchers have also pointed toward the contribution from cometary bodies (Nesvorný et al. 2010, 2011). The particles that are generated by asteroidal collisions have better gravitational focusing and enter an Earth resonance orbit at much lower velocities compared to cometary bodies (Flynn 1989a, 1989b; Brownlee 2001; Kortenkamp et al. 2001). The complexity of entry phenomena is reinforced by considering the combination of physical and chemical parameters and using different geometrical arrangements for the entry of particles.

\section{ABLATION}

Ablation is the result of vaporization that leads to a loss of mass that thereby changes the initial elemental composition as it enters the Earth's atmosphere. The amount of ablation depends on entry parameters such as velocity, ZA, the size of the particle, and the initial composition. It is interesting to see how the particles interact with Earth's atmosphere, generating large-scale heating due to collision with air molecules, and then 
Table 1

The Data for Total Mass Ablated (\%) and the Time (s) the Particles Remain at the Peak Temperature within 200 K (Provided in Brackets) for Various Sizes, ZAs, and Entry Velocities

\begin{tabular}{|c|c|c|c|c|c|c|c|c|c|c|c|}
\hline Entry Velocity & Size $(\mu \mathrm{m})$ & $\mathrm{ZA}=0^{\circ}$ & $10^{\circ}$ & $20^{\circ}$ & $30^{\circ}$ & $40^{\circ}$ & $50^{\circ}$ & $60^{\circ}$ & $70^{\circ}$ & $80^{\circ}$ & $90^{\circ}$ \\
\hline \multirow[t]{6}{*}{$11 \mathrm{~km} \mathrm{~s}^{-1}$} & 100 & $1[1.41]$ & 1 [1.43] & $0[1.42]$ & 0 [1.44] & $0[1.46]$ & 0 [1.49] & $0[1.54]$ & 0 & 0 & 0 \\
\hline & 200 & $3[1.28]$ & 3 [1.28] & 3 [1.29] & 2 [1.29] & $2[1.29]$ & $1[1.34]$ & $1[1.36]$ & 0 & 0 & 0 \\
\hline & 300 & $16[1.24]$ & $15[1.24]$ & $13[1.24]$ & $10[1.24]$ & $7[1.25]$ & $4[1.26]$ & $2[1.26]$ & 0 & 0 & 0 \\
\hline & 500 & $42[1.21]$ & $41[1.22]$ & 38 [1.22] & 33 [1.20] & $25[1.22]$ & $16[1.22]$ & $8[1.21]$ & 0 & 0 & 0 \\
\hline & 600 & $57[1.23]$ & 56 [1.23] & $54[1.22]$ & $49[1.22]$ & $42[1.21]$ & 31 [1.22] & 18 [1.19] & 0 & 0 & 0 \\
\hline & 700 & 65 [1.23] & $64[1.24]$ & $62[1.22]$ & 58 [1.23] & $51[1.21]$ & $41[1.20]$ & $26[1.18]$ & 0 & 0 & 0 \\
\hline & 200 & $76[0.76]$ & $75[0.77]$ & $72[0.77]$ & $67[0.78]$ & $59[0.79]$ & $45[0.81]$ & $26[0.84]$ & 8 [1.09] & 0 & 0 \\
\hline & 300 & $93[0.69]$ & $93[0.69]$ & $92[0.69]$ & $89[0.70]$ & $85[0.73]$ & $77[0.75]$ & $62[0.74]$ & $35[0.81]$ & 0 & 0 \\
\hline & 400 & $96[0.68]$ & $95[0.69]$ & $95[0.69]$ & $95[0.69]$ & $94[0.68]$ & $90[0.70]$ & $80[0.70]$ & $58[0.77]$ & 0 & 0 \\
\hline & 500 & $96[0.53]$ & $96[0.55]$ & $96[0.60]$ & 95 [0.69] & $95[0.68]$ & 93 [0.69] & $86[0.68]$ & $67[0.76]$ & 0 & 0 \\
\hline & 600 & $97[0.34]$ & $97[0.36]$ & $97[0.38]$ & $97[0.45]$ & $96[0.54]$ & $95[0.65]$ & $93[0.68]$ & $81[0.72]$ & 0 & 0 \\
\hline & 700 & 97 [0.29] & 97 [0.29] & 97 [0.29] & $97[0.35]$ & $97[0.43]$ & 96 [0.57] & $95[0.67]$ & $87[0.70]$ & 0 & 0 \\
\hline
\end{tabular}

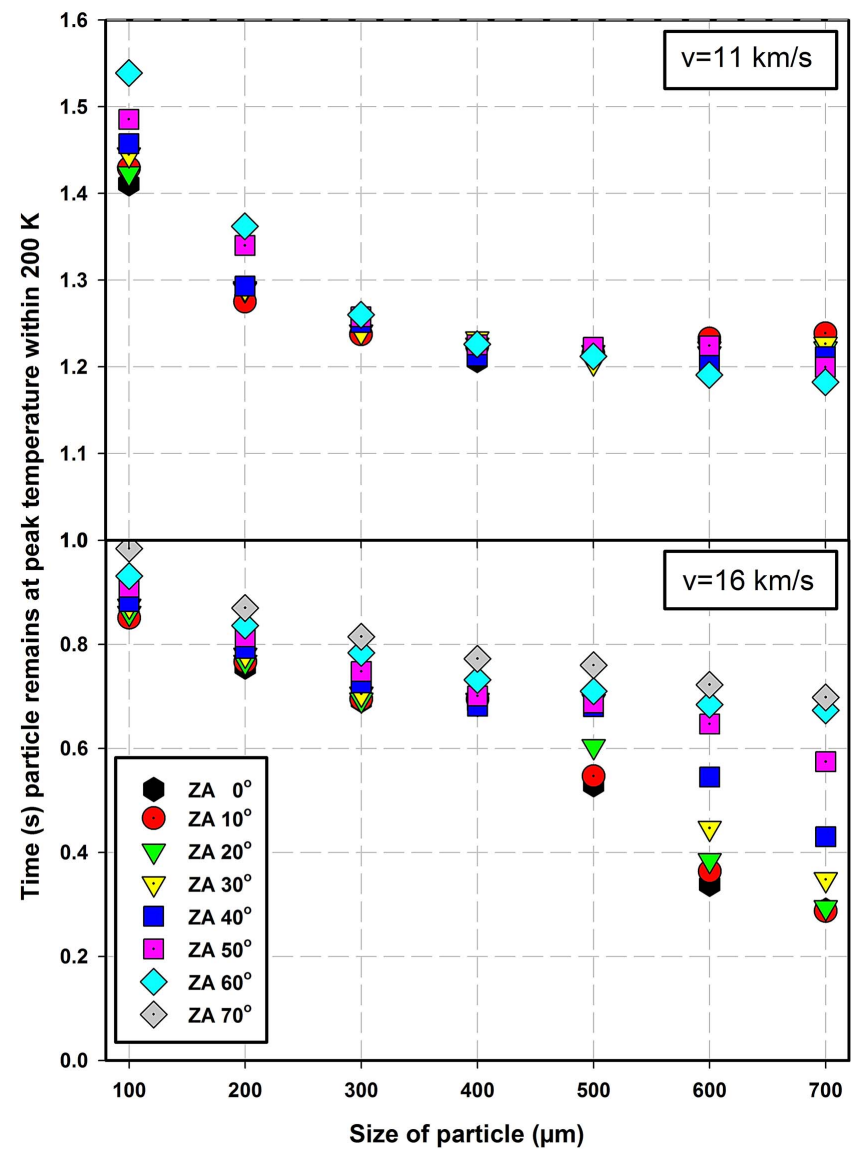

Figure 2. The time particles remain at the peak temperature within $200 \mathrm{~K}$ vs. the size of particles for various ZAs. The time spent at the peak temperature for $16 \mathrm{~km} \mathrm{~s}^{-1}$ is much lower than that of $11 \mathrm{~km} \mathrm{~s}^{-1}$. The ZAs $80^{\circ}$ and $90^{\circ}$ for both entry velocities $\left(11\right.$ and $16 \mathrm{~km} \mathrm{~s}^{-1}$ ) are excluded due to a lack of ablation. In addition, the ZA $70^{\circ}$ for $v=11 \mathrm{~km} \mathrm{~s}^{-1}$ is also not included due to the nonexistence of ablation.

experiencing ablation and changes in chemical composition. It is clear from Figure 1 that irrespective of entry velocity, ablation occurs at an altitude around $70-90 \mathrm{~km}$. The instantaneous mass ablation represented in Figure 1 is a percentage of the mass ablated for each $100 \mathrm{~m}$ decrease in altitude of the particle relative to the initial mass of the particle. The ablation or instantaneous ablation depends on the temperature that the particle reaches during its entry into the atmosphere, and terminates when the temperature and velocity drop beyond the point at which the partial or fully molten particle solidifies. Particles at high ZA travel at a low atmospheric density for longer times because their frictional heating fails to generate enough heat to raise the temperature and lead to minimum mass-loss. The time elapsed by the particle within $100 \mathrm{~K}$ of the peak temperature for particles with sizes of $10-20 \mu \mathrm{m}$ is $\sim 2 \mathrm{~s}$ (Flynn 1989a, 1989b). In the present study we consider the time elapsed by the particle at a peak temperature within $200 \mathrm{~K}$, for sizes from 100 to $700 \mu \mathrm{m}$, as we believe the spread will have a substantial effect on modifying the chemical composition. The time that particles spend at the peak temperature varies for different sizes, ZAs, and entry velocities, as seen in Table 1. The time spent for large particles in size ranges from $\sim 100$ to $\sim 700 \mu \mathrm{m}$ is from 0.3 to $1 \mathrm{~s}$ for various ZAs at an entry velocity of $16 \mathrm{~km} \mathrm{~s}^{-1}$, while it is $1.2-1.5 \mathrm{~s}$ for those with an entry velocity of $11 \mathrm{~km} \mathrm{~s}^{-1}$ (Figure 2). Consider two different entry velocities. (a) $16 \mathrm{~km} \mathrm{~s}^{-1}$ : the change in $\mathrm{ZA}$ does not change the time spent at the peak temperature up to $400 \mu \mathrm{m}$; beyond this size $(>500 \mu \mathrm{m})$ at lower ZA $\left(0^{\circ}-40^{\circ}\right)$ the time at peak temperature shortens drastically. However, for ZAs above $50^{\circ}$ the time change is within $\pm 0.3 \mathrm{~s}$ for any size. (b) $11 \mathrm{~km} \mathrm{~s}^{-1}$ : the change in ZA does not change the time that the particle remains at the peak temperature for sizes $>300 \mu \mathrm{m}$. There is an increase in the time at peak temperature below $300 \mu \mathrm{m}$, e.g., the time elapsed for $\sim 200 \mu \mathrm{m}$ at any ZA is $\sim 1.3 \mathrm{~s}$, while for $\sim 100 \mu \mathrm{m}$ it is $\sim 1.4-1.5 \mathrm{~s}$ (Figure 2).

The understanding gained with respect to ZA is that particles with larger sizes and smaller ZAs spend less time at the peak temperature compared to particles with large ZAs. Furthermore, those with higher entry velocities spend less time at the peak temperature than particles that enter with lower entry velocities. Although the time difference is trivial, the extent of the modification to the particles is not insignificant. A change in heating time for a fraction of a second at the peak temperature can alter the ablation significantly. It can be seen in Figure 2, at $16 \mathrm{~km} \mathrm{~s}^{-1}$ for $200 \mu \mathrm{m}$, that the time spent at the peak temperature for ZA $0^{\circ}$ is $0.76 \mathrm{~s}$, while that for ZA $60^{\circ}$ is $0.84 \mathrm{~s}$. For $11 \mathrm{~km} \mathrm{~s}^{-1}$, at ZA $0^{\circ}$ the time spent is $1.28 \mathrm{~s}$ and that for ZA $60^{\circ}$ is $1.36 \mathrm{~s}$. However, at $11 \mathrm{~km} \mathrm{~s}^{-1}$ and a size of $700 \mu \mathrm{m}$ the time at the peak temperature for various ZAs is 
Table 2

The Peak Temperature (K) Attained by Particles of Various Sizes and Entry Parameters

\begin{tabular}{lcccccccccc}
\hline \hline Entry Velocity & Size $(\mu \mathrm{m})$ & $\mathrm{ZA}=0^{\circ}$ & $10^{\circ}$ & $20^{\circ}$ & $30^{\circ}$ & $40^{\circ}$ & $50^{\circ}$ & $60^{\circ}$ & $70^{\circ}$ & $80^{\circ}$ \\
\hline $11 \mathrm{~km} \mathrm{~s}^{-1}$ & 100 & 1741 & 1735 & 1718 & 1687 & 1640 & 1577 & 1492 & 750 & 156 \\
& 200 & 2071 & 2064 & 2043 & 2007 & 1953 & 1880 & 1781 & 671 & 163 \\
& 300 & 2288 & 2282 & 2261 & 2226 & 2172 & 2095 & 1989 & 560 & 169 \\
& 400 & 2412 & 2407 & 2389 & 2357 & 2308 & 2235 & 2130 & 485 & 173 \\
& 500 & 2459 & 2454 & 2437 & 2408 & 2361 & 2292 & 2189 & 457 & 175 \\
& 600 & 2544 & 2539 & 2524 & 2498 & 2456 & 2395 & 2301 & 407 & 179 \\
& 700 & 2591 & 2586 & 2572 & 2546 & 2507 & 2449 & 2361 & 382 & 181 \\
\hline $16 \mathrm{~km} \mathrm{~s}^{-1}$ & 100 & 2257 & 2250 & 2228 & 2190 & 2131 & 2047 & 1930 & 1767 & 189 \\
& 200 & 2552 & 2547 & 2529 & 2499 & 2452 & 2383 & 2277 & 2107 & 182 \\
& 300 & 2697 & 2693 & 2680 & 2657 & 2619 & 2561 & 2470 & 2323 & 182 \\
& 400 & 2780 & 2770 & 2758 & 2737 & 2705 & 2657 & 2579 & 2445 & 184 \\
& 500 & 2892 & 2880 & 2840 & 2769 & 2738 & 2692 & 2620 & 2494 & 185 \\
& 600 & 3040 & 3033 & 3008 & 2961 & 2876 & 2756 & 2692 & 2582 & 186 \\
& 700 & 3106 & 3099 & 3078 & 3040 & 2975 & 2852 & 2729 & 2628 & 187 \\
\hline
\end{tabular}

$1.18-1.23 \mathrm{~s}$. This spread is narrow compared to $16 \mathrm{~km} \mathrm{~s}^{-1}$, as can be seen in Figure 2. The ZAs $>60^{\circ}$ for $11 \mathrm{~km} \mathrm{~s}^{-1}$ and ZAs $>70^{\circ}$ for $16 \mathrm{~km} \mathrm{~s}^{-1}$ are not plotted in Figure 2, as the particle does not experience temperatures that can alter the chemical composition. It is noteworthy for 11 and $16 \mathrm{~km} \mathrm{~s}^{-1}$ at ZAs $70^{\circ}-90^{\circ}$ and ZAs $80^{\circ}-90^{\circ}$, respectively, that the peak temperature is insignificant and the time spent at peak temperature is of no consequence (Table 2). The particles with higher velocities penetrate Earth's atmosphere within smaller intervals of time, thereby generating large frictional heating, which is required to ablate their mass. The distances traveled by the particles from the beginning to the end of ablation, for entry velocities of 11 and $16 \mathrm{~km} \mathrm{~s}^{-1}$, are more or less similar for various ZAs, except at $11 \mathrm{~km} \mathrm{~s}^{-1}$, particle ablation starts slightly later compared to that at $16 \mathrm{~km} \mathrm{~s}^{-1}$ (Figure 1). Also, the particle entering at ZA $0^{\circ}$ penetrates slightly deeper into the Earth's atmosphere than compared to those with higher ZAs (Figure 1). The first narrow peak corresponds to the ablation of the volatile elements (such as $\mathrm{Na}$ and $\mathrm{K}$ ), which starts at an altitude of $\sim 90 \mathrm{~km}$, where their vaporization is complete (Figure 1). Further penetration of particles deeper into the atmosphere raises the temperature due to friction, where major and less volatile elements such as $\mathrm{Fe}, \mathrm{Mg}$, $\mathrm{Si}$ experience ablation, which is reflected in the second broader peak of Figure 1. For refractory elements such as $\mathrm{Ca}$ and $\mathrm{Al}$, ablation depends strongly on having a larger size, higher entry velocity, and smaller ZA (Vondrak et al. 2008). The ablation percentage versus the altitude at every step of $100 \mathrm{~m}$ demonstrates that the ablation percentage is very small for $11 \mathrm{~km} \mathrm{~s}^{-1}$ compared to $16 \mathrm{~km} \mathrm{~s}^{-1}$. For a $200 \mu \mathrm{m}$ particle size and lower ZA, the ablation percentage at every $100 \mathrm{~m}$ is $\sim 10$ times more for $16 \mathrm{~km} \mathrm{~s}^{-1}$ than compared to $11 \mathrm{~km} \mathrm{~s}^{-1}$. Similarly, for $300 \mu \mathrm{m}$ it is $\sim 7$ times and for $400 \mu \mathrm{m}$ it is $\sim 3$ times (Figure 1). This suggests that for different entry velocities, 11 and $16 \mathrm{~km} \mathrm{~s}^{-1}$, there is a difference in the ablation percentage for smaller sizes, but the differences decrease for larger particles. Furthermore, the curve of $\mathrm{ZA} 0^{\circ}$ is broader than that of higher ZAs for any velocity. At an entry velocity of $16 \mathrm{~km} \mathrm{~s}^{-1}$ the ablation curve starts from higher altitudes compared to $11 \mathrm{~km} \mathrm{~s}^{-1}$, due to the generation of heat during the interaction with air molecules at higher altitudes. This is true for all sizes and different entry velocities. The larger instantaneous ablation will change the original chemical composition, and the ablated material will eventually end up as nanometer-sized smoke in the troposphere
(Hunten et al. 1980). Previous detailed ablation studies (e.g., Flynn 1989a, 1989b; Love \& Brownlee 1991) suggest better preservation of smaller particles. This can be seen in Figures $3-$ 4 for entry velocities of 11 and $16 \mathrm{~km} \mathrm{~s}^{-1}$ for various sizes $100-600 \mu \mathrm{m}$. The large ZAs $70^{\circ}-90^{\circ}$ and ZAs $80^{\circ}-90^{\circ}$ have a smaller effect on different sizes for 11 and $16 \mathrm{~km} \mathrm{~s}^{-1}$, respectively, as the ablation is insignificant (Figures 3-4). It should be noted that a particle entering at ZA $90^{\circ}$ with an Earth escape velocity or higher is physically impractical, as it will not descend to enter the atmosphere (Love \& Brownlee 1991). A particle in horizontal flight never changes its height or ablates, as the atmospheric pressure is not high enough at that altitude, thus the particles subsequently escapes back to space (Love \& Brownlee 1991). However, the increase in size and the decrease in ZA result in an increase in ablation and the change in size is relatively large if the entry velocity is amplified from 11 to $16 \mathrm{~km} \mathrm{~s}^{-1}$ (Figures 3-4). Compared to a particle entering at $11 \mathrm{~km} \mathrm{~s}^{-1}$, particle entering at $16 \mathrm{~km} \mathrm{~s}^{-1}$ has less time to be at a peak temperature where it can deposit a large amount of heat and fuel large-scale vaporization.

Particles with an entry velocity of $11 \mathrm{~km} \mathrm{~s}^{-1}$ will continue to ablate until the velocity drops to $\sim 7 \mathrm{~km} \mathrm{~s}^{-1}$; thereafter particles will be brought to thermal equilibrium slowly, alongside the temperature of the surrounding atmosphere. Likewise, for $16 \mathrm{~km} \mathrm{~s}^{-1}$ the ablation will continue until $\sim 7 \mathrm{~km} \mathrm{~s}^{-1}$, but maximum ablation takes places until the particle reaches $\sim 10 \mathrm{~km} \mathrm{~s}^{-1}$ (Figure 5). The large ablation seen in particles with entry velocities of $16 \mathrm{~km} \mathrm{~s}^{-1}$ and sizes $>200 \mu \mathrm{m}$ indicates a loss of those particles' identities before they reach Earth. However, for $11 \mathrm{~km} \mathrm{~s}^{-1}$ particles $>400 \mu \mathrm{m}$ can survive without large ablation (Figure 5). Based on this, if we assume that the incoming particles are uniformly distributed, then the region from ZAs $30^{\circ}-90^{\circ}$ can facilitate survival on Earth's surface for particles with an entry velocity of $11 \mathrm{~km} \mathrm{~s}^{-1}$. If particles are distributed uniformly around the Earth's sphere then this contribution is $\sim 2 / 3(\sim 66 \%)$ of the volume where particles (both melted and unmelted) reach the surface. Analyses of hyper-velocity impact craters found on the space-facing end of the Long Duration Exposure Facility spacecraft estimate micrometeorite fluxes of $\sim 30,000$ tons per annum (Love \& Brownlee 1993). The region (ZAs $30^{\circ}-90^{\circ}$ ) with particle survivability suggests that $\sim 20,000$ tons per annum make it to the Earth's surface, provided all particles are entering at a low entry velocity. Considering that both melted and unmelted 


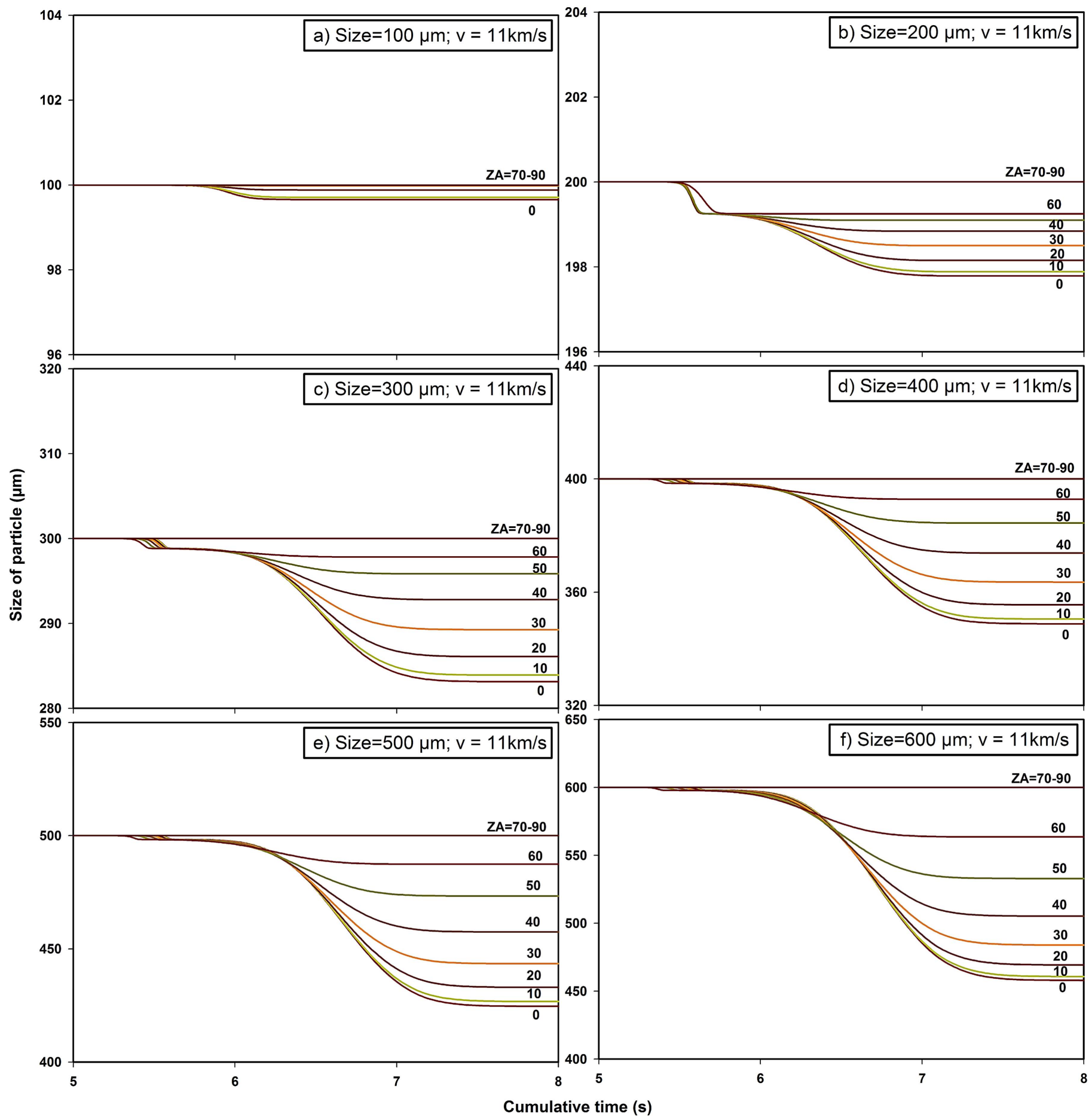

Figure 3. $11 \mathrm{~km} \mathrm{~s}^{-1}$ : the change in size (or diameter) of the particle for different sizes ( $\mu \mathrm{m}$ ) vs. the cumulative time (s) spent by it to enter the Earth's atmosphere. The number on the line in the graph is the ZA.

particles contributes $50 \%$ each to the flux based on studies done on Greenland's ice cap, the Yamato mountains, and the South Pole water well in Antarctica (Maurette et al. 1987; Yada et al. 2004; Taylor et al. 2007), the melted micrometeorites are understood to enter at ZAs $30^{\circ}-60^{\circ}$ and particles entering with lower ZAs than indicated above will have minor contributions. The unmelted particles should make it through ZAs $60^{\circ}-90^{\circ}$. Meteoroids and sporadic meteors' velocity distributions relative to Earth are peaked at $16 \mathrm{~km} \mathrm{~s}^{-1}$ (Erickson 1968; Kessler 1969; Love \& Brownlee 1993). However, there will be some contribution from particles with slightly higher velocities, but that contribution will limit the range of ZA in which a particle can survive, as the ablation of a high-velocity particle will be close to $100 \%$, indicating no residue will be left to reach the surface of Earth (Rudraswami et al. 2015a). The accretion rate based on hand-picking micrometeorites from Antarctica, combined with noble gas analyses from residue, agrees well with the above value (Yada et al. 2004). However, for particles in the size range of $>50 \mu \mathrm{m}$ to a few $\mathrm{mm}$, the flux may be 3000 tons per annum (Taylor et al. 1998). Cziczo et al. (2001), using stratospheric aerosol chemistry, indicated that ablated sub-micron sized meteoritic residues will add 


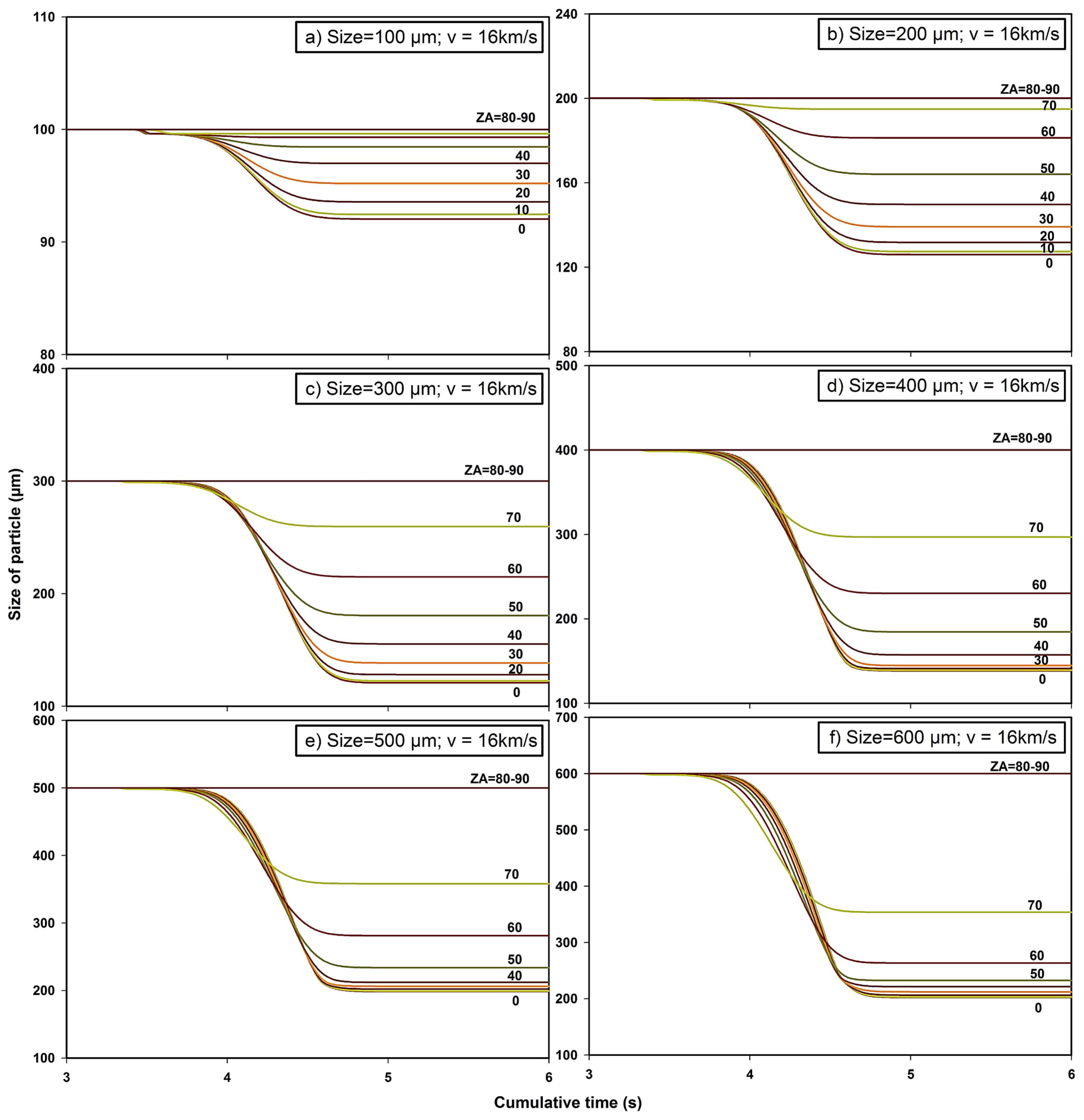

Figure $4.16 \mathrm{~km} \mathrm{~s}^{-1}$ : the change in size (or diameter) of the particle for different sizes ( $\mu \mathrm{m}$ ) vs. the cumulative time (s) spent by it to enter the Earth's atmosphere. The number on the line in the graph is the ZA.

4000-19000 tons per annum (Yada et al. 2004). This evaporated material, along with estimates of handpicked extra-terrestrial particles, agrees with the flux provided by Love \& Brownlee (1993).

\section{VARIATION IN CHEMICAL COMPOSITIONS}

The ablation due to the evaporating mass from the incoming particle results in chemical fractionation that will have quite different initial composition from that of precursor due to its interaction with the atmosphere. The changes in chemical composition depend on the volatility of the elements and are largely disproportionate. Fe, due to its high volatility, undergoes larger ablation than $\mathrm{Si}$, which is slightly more volatile than Mg (Hashimoto 1983). The different elemental compositions (oxide wt\%) of dust particles with bulk CI composition show variation for different entry velocities with different sizes and a range of ZAs (Figures 6-7). The $\mathrm{SiO}_{2}$ and $\mathrm{FeO}$ variation changes the stoichiometry of particles, largely depending on various entry parameters, which are discussed below. 

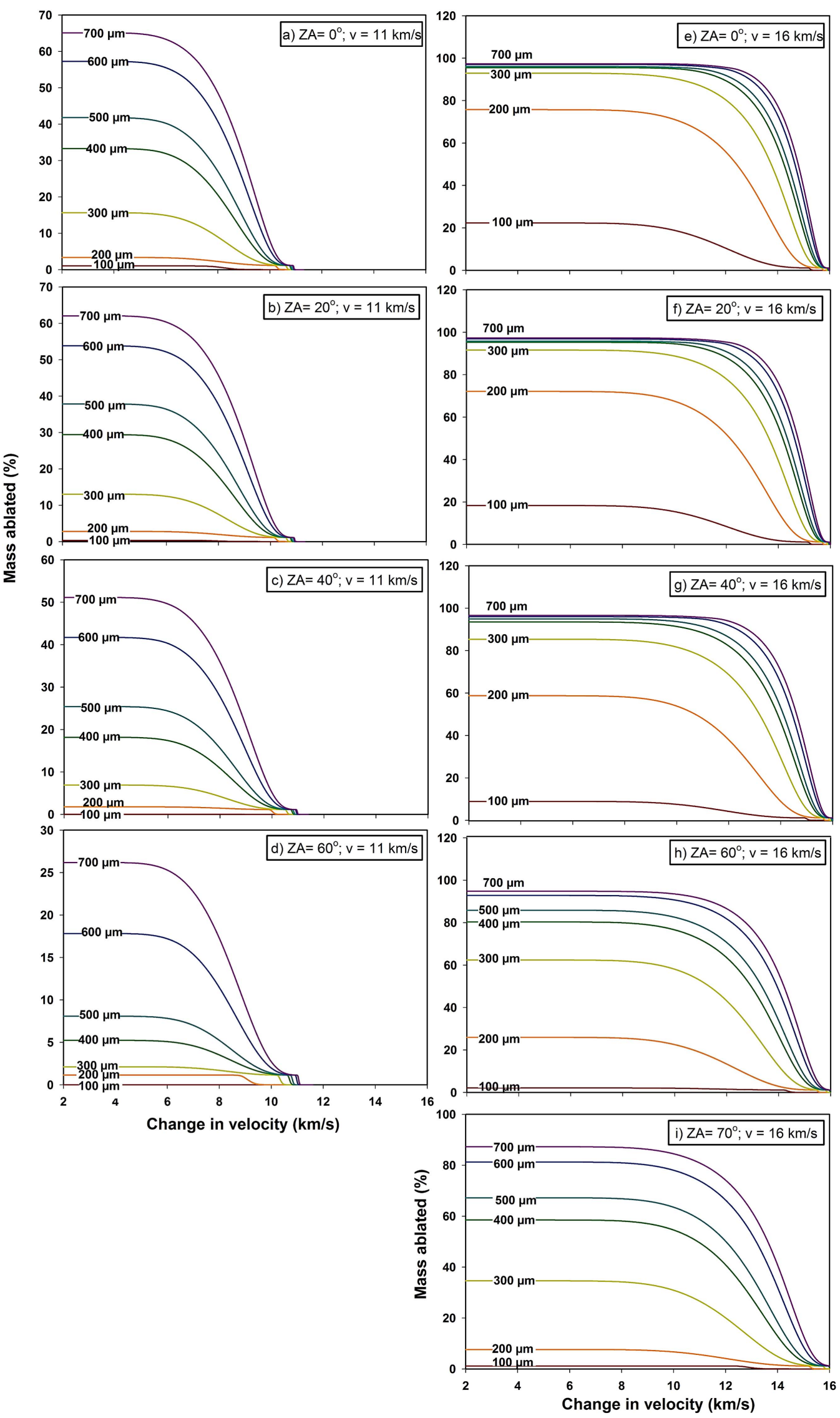

Figure 5. The change in velocity of the particle as it enters the Earth's atmosphere with respect to the percentage of mass ablated for various sizes marked on the line for different ZAs and entry velocities. The ZA $70^{\circ}$ for $11 \mathrm{~km} \mathrm{~s}^{-1}$ is not plotted, as there is no ablation, while for $16 \mathrm{~km} \mathrm{~s}^{-1}$ the ablation starts to drop. 


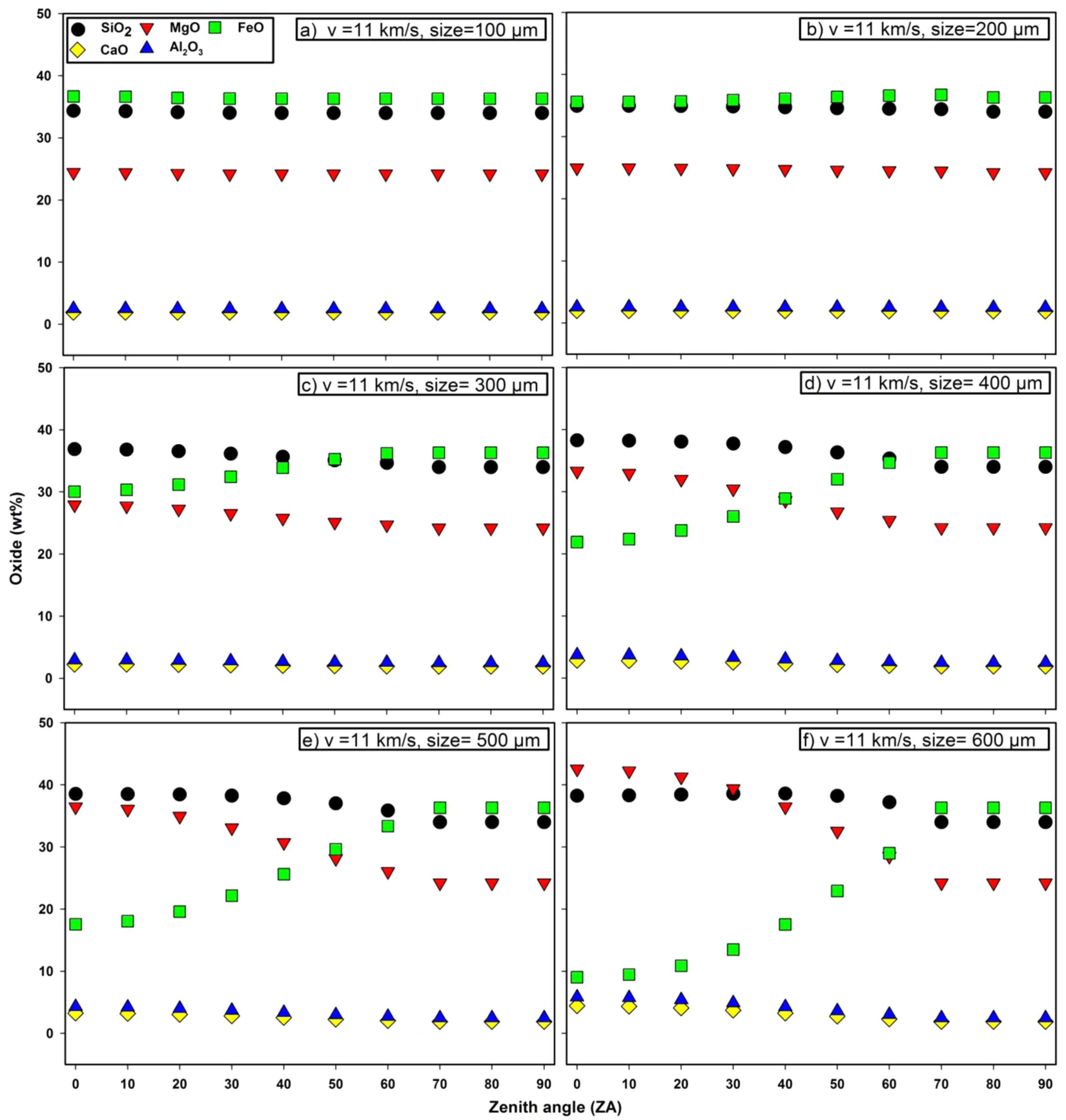

Figure 6. $11 \mathrm{~km} \mathrm{~s}^{-1}$ : change in oxide composition (wt $\%$ ) of $\mathrm{MgO}, \mathrm{SiO}_{2}, \mathrm{FeO}, \mathrm{Al}_{2} \mathrm{O}_{3}$, and $\mathrm{CaO}$ for various sizes vs. the $\mathrm{ZA}$. The composition at $\mathrm{ZA} 90^{\circ}$ is the initial composition of the particle, which is the CI composition.

The entry velocity of $11 \mathrm{~km} \mathrm{~s}^{-1}$ shows small variation in all major elements for particle sizes of $\sim 100 \mu \mathrm{m}$ irrespective of any ZA. However, for particle sizes $\sim 200 \mu \mathrm{m}, \mathrm{FeO}$ starts to deviate slightly by a few percent at lower ZAs below $30^{\circ}$, due to vaporization during the atmospheric entry, as can be seen in Figure 6. Nevertheless, the normalized values of $\mathrm{Mg} / \mathrm{Si}$ and $\mathrm{Fe} / \mathrm{Si}$ are close to $\mathrm{CI}$ values (Figure 8, Table 3). Beyond this size, the variation for all major elements $(\mathrm{Mg}, \mathrm{Si}, \mathrm{Fe})$ deviates but is dominated by $\mathrm{FeO}$. The enrichment of $\mathrm{MgO}$ and $\mathrm{SiO}_{2}$ is compensated by the depletion of $\mathrm{FeO}$. The peak temperature attained by the particle, resulting in mass-loss, plays a vital role in determining these elemental losses for various sizes and ZAs (Figure 9 and Table 2). Higher temperatures decrease the quantity of $\mathrm{FeO}$ due to vaporization (Hashimoto 1983). The
$\mathrm{FeO}$ does not extinguish at $11 \mathrm{~km} \mathrm{~s}^{-1}$ but is substantially depleted for large particles beyond $300 \mu \mathrm{m}$. The change is not significantly reflected in the elemental ratio (Table 3). The interpretation based on the model result is consistent with experimental work done by Hashimoto (1983). The more refractory elements $\mathrm{Ca}$ and $\mathrm{Al}$ do not alter significantly for any size and any ZA at the entry velocity $11 \mathrm{~km} \mathrm{~s}^{-1}$. Large volatility is clear from the $\mathrm{Fe} / \mathrm{Si}$ ratio, where $\mathrm{Fe} / \mathrm{Si}$ drops toward zero steadily for larger particle sizes at 11 and for $16 \mathrm{~km} \mathrm{~s}^{-1}$ the drop is rapid (Figure 8). The change in composition begins with an entry velocity of $16 \mathrm{~km} \mathrm{~s}^{-1}$ and vaporization of volatile element $\mathrm{FeO}$. Once the $\mathrm{FeO}$ diminution reaches beyond $50 \%$, the reversal of volatility takes place between $\mathrm{SiO}_{2}$ and $\mathrm{MgO}$, where $\mathrm{MgO}$ become more volatile 


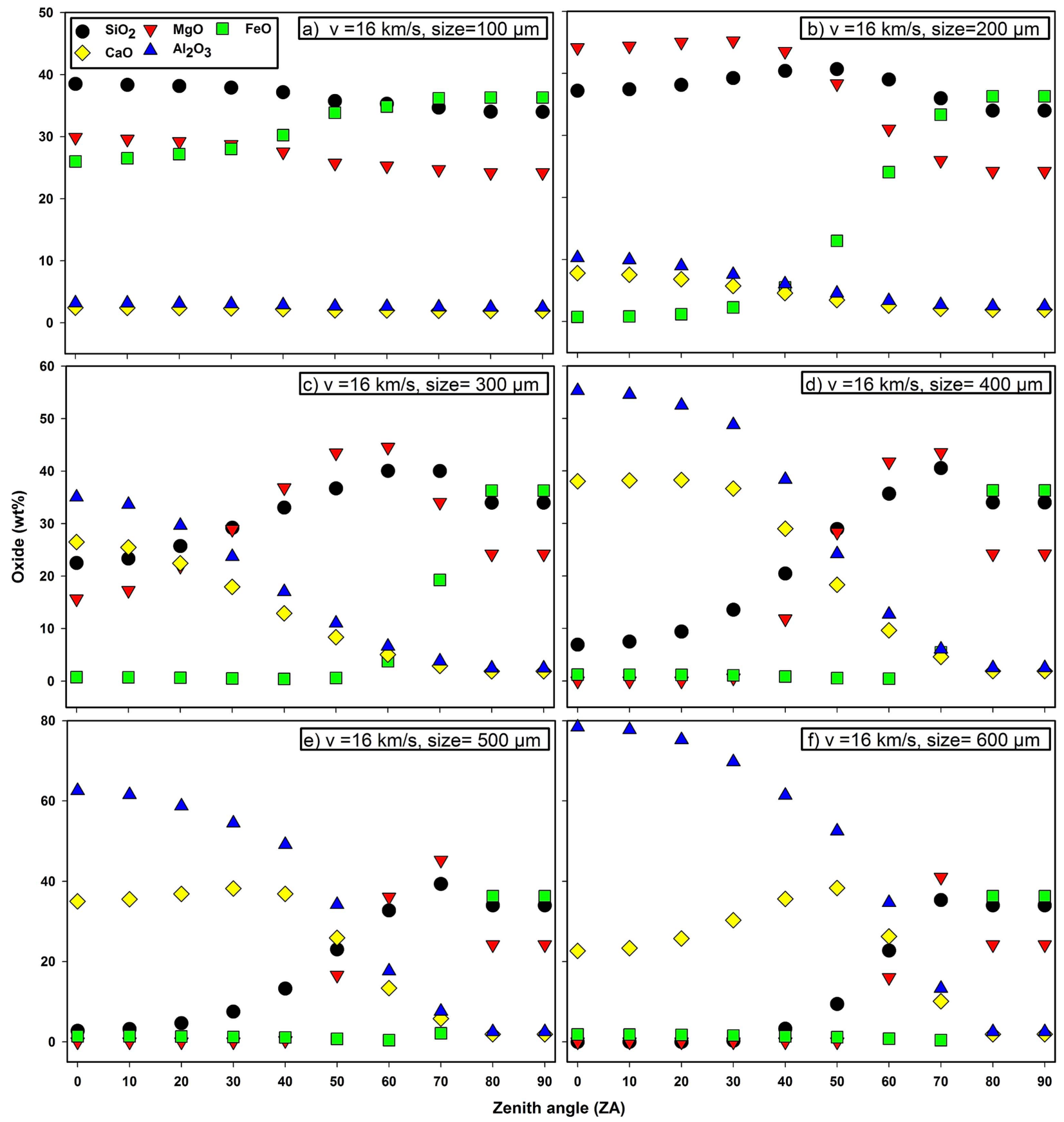

Figure 7. $16 \mathrm{~km} \mathrm{~s}^{-1}$ : change in oxide composition (wt\%) of $\mathrm{MgO}, \mathrm{SiO}_{2}, \mathrm{FeO}, \mathrm{Al}_{2} \mathrm{O}_{3}$, and $\mathrm{CaO}$ for various sizes vs. the $\mathrm{ZA}$. The composition at $\mathrm{ZA} 90^{\circ}$ is the initial composition of the particle, which is the CI composition.

than $\mathrm{SiO}_{2}$, as can be seen in Figure 7 (Hashimoto 1983). The $\mathrm{Mg} / \mathrm{Si}$ for $16 \mathrm{~km} \mathrm{~s}^{-1}$ raises rapidly and reaches close to $\sim 1.6$ (normalized to CI), then thereafter drops for all ZAs at larger sizes, due to large $\mathrm{Mg}$ ablation in the melt, followed by that of Si (Figure 8, Table 3). ZAs $0^{\circ}-30^{\circ}$ for $\mathrm{Mg} / \mathrm{Si}$ peak at $200 \mu \mathrm{m}$ and then drop sharply close to zero. This is due to initial Si loss that is dominant over the $\mathrm{Mg}$, and subsequently $\mathrm{Mg}$ loss predominates. Nevertheless, the larger ZA has an elemental ratio value peak shift to larger sizes and the fall is also not as sharp as what we see at lower ZAs. This is not the case with $\mathrm{Fe} / \mathrm{Si}$, where the ratio keeps on falling, except at larger sizes beyond $400 \mu \mathrm{m}$ and lower ZAs, there are fluctuations where most of the material is ablated. $\mathrm{Ca} / \mathrm{Si}$ and $\mathrm{Al} / \mathrm{Si}$ are continuously increasing due to large ablation of $\mathrm{Si}$, leading to enrichment of $\mathrm{Ca}$ and $\mathrm{Al}$ (Table 3 ). The theoretical prediction for $16 \mathrm{~km} \mathrm{~s}^{-1}$ beyond $400 \mu \mathrm{m}$ and at lower ZA $0^{\circ}-30^{\circ}$ is that the particle is left with only $\mathrm{Ca}$ and $\mathrm{Al}$, due to the ablation of all major elements suspended in the atmospheric cloud (Figure 7). $\mathrm{Ca}$ and $\mathrm{Al}$ have long been recognized as refractory elements, which, under favorable conditions, undergo phase changes to become hibonite or corundum, depending on the concentration of the elements present after progressive loss of the major elements.

\section{CONCLUSIONS}

The chemical evolution of micrometeorite particles as they enter Earth's atmosphere plays a vital role in delineating which 

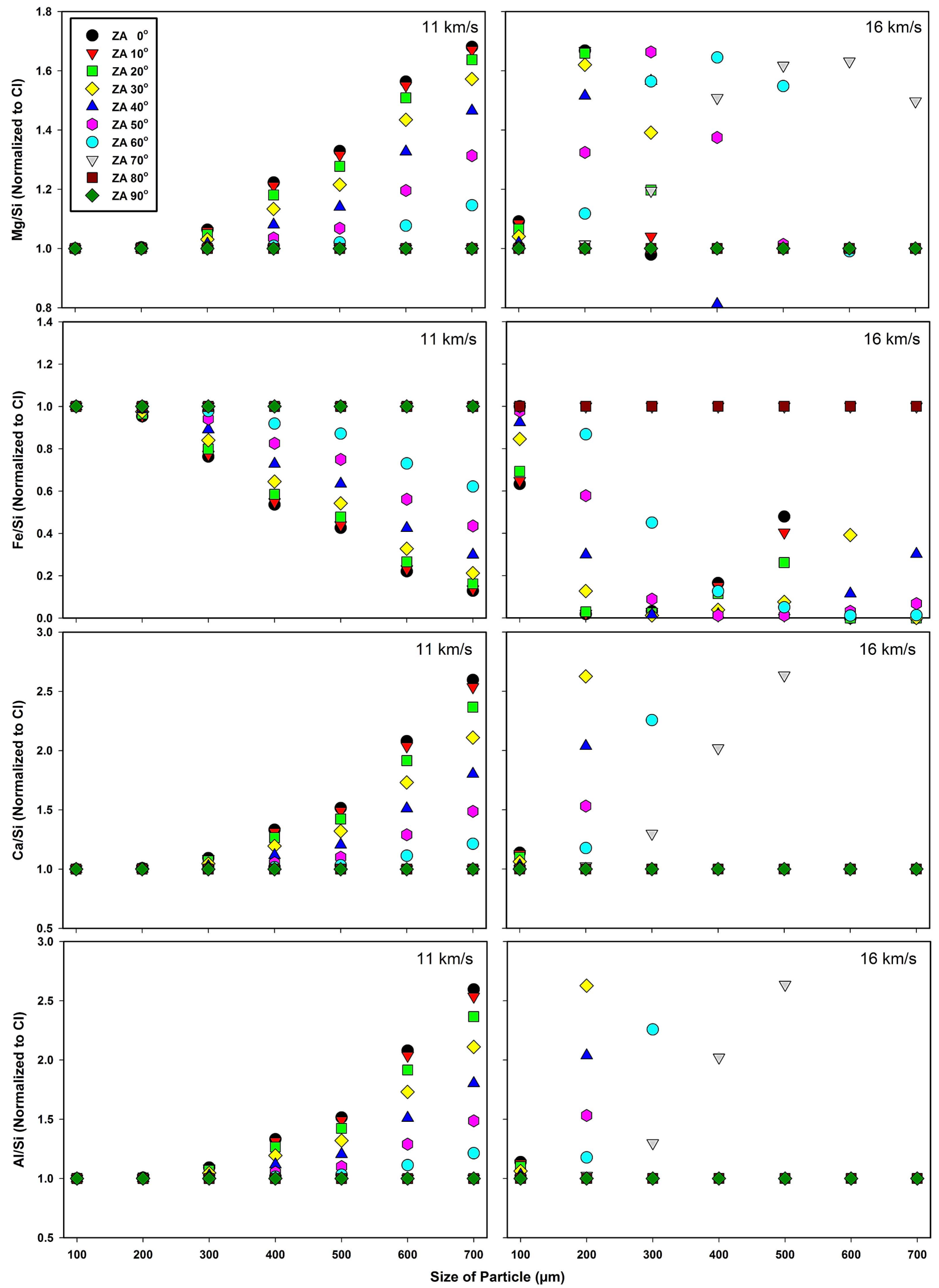

Figure 8. The elemental $\mathrm{Mg} / \mathrm{Si}, \mathrm{Fe} / \mathrm{Si}, \mathrm{Ca} / \mathrm{Si}$, and $\mathrm{Al} / \mathrm{Si}$ (normalized to $\mathrm{CI}$ ) for different sizes and $\mathrm{ZAs}$. The number on the line in the graph is the $\mathrm{ZA}$. 
Table 3

The Elemental Ratios Normalized to CI for Various Sizes, ZAs, and Entry Velocities

\begin{tabular}{|c|c|c|c|c|c|c|c|c|c|c|c|}
\hline Entry Velocity & Size $(\mu \mathrm{m})$ & $\mathrm{ZA}=0^{\circ}$ & $10^{\circ}$ & $20^{\circ}$ & $30^{\circ}$ & $40^{\circ}$ & $50^{\circ}$ & $60^{\circ}$ & $70^{\circ}$ & $80^{\circ}$ & $90^{\circ}$ \\
\hline \multicolumn{12}{|c|}{ (a) Final $\mathrm{Mg} / \mathrm{Si}$ Values (Normalized to $\mathrm{CI}$ ) } \\
\hline \multirow[t]{7}{*}{$11 \mathrm{~km} \mathrm{~s}^{-1}$} & 100 & 1.0 & 1.0 & 1.0 & 1.0 & 1.0 & 1.0 & 1.0 & 1.0 & 1.0 & 1.0 \\
\hline & 200 & 1.0 & 1.0 & 1.0 & 1.0 & 1.0 & 1.0 & 1.0 & 1.0 & 1.0 & 1.0 \\
\hline & 300 & 1.1 & 1.1 & 1.0 & 1.0 & 1.0 & 1.0 & 1.0 & 1.0 & 1.0 & 1.0 \\
\hline & 400 & 1.2 & 1.2 & 1.2 & 1.1 & 1.1 & 1.0 & 1.0 & 1.0 & 1.0 & 1.0 \\
\hline & 500 & 1.3 & 1.3 & 1.3 & 1.2 & 1.1 & 1.1 & 1.0 & 1.0 & 1.0 & 1.0 \\
\hline & 600 & 1.6 & 1.6 & 1.5 & 1.4 & 1.3 & 1.2 & 1.1 & 1.0 & 1.0 & 1.0 \\
\hline & 700 & 1.7 & 1.7 & 1.6 & 1.6 & 1.5 & 1.3 & 1.1 & 1.0 & 1.0 & 1.0 \\
\hline \multirow[t]{7}{*}{$16 \mathrm{~km} \mathrm{~s}^{-1}$} & 100 & 1.1 & 1.1 & 1.1 & 1.0 & 1.0 & 1.0 & 1.0 & 1.0 & 1.0 & 1.0 \\
\hline & 200 & 1.7 & 1.7 & 1.7 & 1.6 & 1.5 & 1.3 & 1.1 & 1.0 & 1.0 & 1.0 \\
\hline & 300 & 1.0 & 1.0 & 1.2 & 1.4 & 1.6 & 1.7 & 1.6 & 1.2 & 1.0 & 1.0 \\
\hline & 400 & $\ldots$ & $\cdots$ & $\ldots$ & 0.1 & 0.8 & 1.4 & 1.6 & 1.5 & 1.0 & 1.0 \\
\hline & 500 & $\cdots$ & $\cdots$ & $\cdots$ & $\ldots$ & 0.0 & 1.0 & 1.5 & 1.6 & 1.0 & 1.0 \\
\hline & 600 & $\ldots$ & $\ldots$ & $\ldots$ & $\ldots$ & $\ldots$ & $\ldots$ & 1.0 & 1.6 & 1.0 & 1.0 \\
\hline & 700 & $\cdots$ & $\cdots$ & $\ldots$ & $\ldots$ & $\ldots$ & $\ldots$ & 0.1 & 1.5 & 1.0 & 1.0 \\
\hline
\end{tabular}

(b) Final $\mathrm{Fe} / \mathrm{Si}$ values (Normalized to $\mathrm{CI}$ )

\begin{tabular}{|c|c|c|c|c|c|c|c|c|c|c|c|}
\hline \multirow[t]{7}{*}{$11 \mathrm{~km} \mathrm{~s}^{-1}$} & 100 & 1.0 & 1.0 & 1.0 & 1.0 & 1.0 & 1.0 & 1.0 & 1.0 & 1.0 & 1.0 \\
\hline & 200 & 1.0 & 1.0 & 1.0 & 1.0 & 1.0 & 1.0 & 1.0 & 1.0 & 1.0 & 1.0 \\
\hline & 300 & 0.8 & 0.8 & 0.8 & 0.8 & 0.9 & 0.9 & 1.0 & 1.0 & 1.0 & 1.0 \\
\hline & 400 & 0.5 & 0.5 & 0.6 & 0.6 & 0.7 & 0.8 & 0.9 & 1.0 & 1.0 & 1.0 \\
\hline & 500 & 0.4 & 0.4 & 0.5 & 0.5 & 0.6 & 0.7 & 0.9 & 1.0 & 1.0 & 1.0 \\
\hline & 600 & 0.2 & 0.2 & 0.3 & 0.3 & 0.4 & 0.6 & 0.7 & 1.0 & 1.0 & 1.0 \\
\hline & 700 & 0.1 & 0.1 & 0.2 & 0.2 & 0.3 & 0.4 & 0.6 & 1.0 & 1.0 & 1.0 \\
\hline \multirow[t]{7}{*}{$16 \mathrm{~km} \mathrm{~s}^{-1}$} & 100 & 0.6 & 0.6 & 0.7 & 0.8 & 0.8 & 0.9 & 1.0 & 1.0 & 1.0 & \\
\hline & 200 & 0.0 & 0.0 & 0.0 & 0.1 & 0.1 & 0.3 & 0.6 & 0.9 & 1.0 & \\
\hline & 300 & 0.0 & 0.0 & 0.0 & 0.0 & 0.0 & 0.0 & 0.1 & 0.5 & 1.0 & \\
\hline & 400 & 0.2 & 0.2 & 0.1 & 0.1 & 0.0 & 0.0 & 0.0 & 0.1 & 1.0 & \\
\hline & 500 & 0.5 & 0.4 & 0.3 & 0.1 & 0.1 & 0.0 & 0.0 & 0.1 & 1.0 & \\
\hline & 600 & $\cdots$ & $\ldots$ & $\cdots$ & 5.6 & 0.4 & 0.1 & 0.0 & 0.0 & 1.0 & \\
\hline & 700 & $\ldots$ & $\ldots$ & $\ldots$ & $\cdots$ & $\ldots$ & 0.3 & 0.1 & 0.0 & 1.0 & \\
\hline
\end{tabular}

(c) Final $\mathrm{Ca} / \mathrm{Si}$ values (Normalized to $\mathrm{CI}$ )

\begin{tabular}{|c|c|c|c|c|c|c|c|c|c|c|c|}
\hline \multirow[t]{7}{*}{$11 \mathrm{~km} \mathrm{~s}^{-1}$} & 100 & 1.0 & 1.0 & 1.0 & 1.0 & 1.0 & 1.0 & 1.0 & 1.0 & 1.0 & 1.0 \\
\hline & 200 & 1.0 & 1.0 & 1.0 & 1.0 & 1.0 & 1.0 & 1.0 & 1.0 & 1.0 & 1.0 \\
\hline & 300 & 1.1 & 1.1 & 1.1 & 1.0 & 1.0 & 1.0 & 1.0 & 1.0 & 1.0 & 1.0 \\
\hline & 400 & 1.3 & 1.3 & 1.3 & 1.2 & 1.1 & 1.1 & 1.0 & 1.0 & 1.0 & 1.0 \\
\hline & 500 & 1.5 & 1.5 & 1.4 & 1.3 & 1.2 & 1.1 & 1.0 & 1.0 & 1.0 & 1.0 \\
\hline & 600 & 2.1 & 2.0 & 1.9 & 1.7 & 1.5 & 1.3 & 1.1 & 1.0 & 1.0 & 1.0 \\
\hline & 700 & 2.6 & 2.5 & 2.4 & 2.1 & 1.8 & 1.5 & 1.2 & 1.0 & 1.0 & 1.0 \\
\hline \multirow[t]{7}{*}{$16 \mathrm{~km} \mathrm{~s}^{-1}$} & 100 & 1.1 & 1.1 & 1.1 & 1.1 & 1.0 & 1.0 & 1.0 & 1.0 & 1.0 & 1.0 \\
\hline & 200 & 3.8 & 3.6 & 3.2 & 2.6 & 2.0 & 1.5 & 1.2 & 1.0 & 1.0 & 1.0 \\
\hline & 300 & 21 & 20 & 16 & 11 & 7.0 & 4.1 & 2.3 & 1.3 & 1.0 & 1.0 \\
\hline & 400 & 99 & 92 & 73 & 48 & 25 & 11 & 4.8 & 2.0 & 1.0 & 1.0 \\
\hline & 500 & 231 & 201 & 142 & 91 & 50 & 20 & 7.3 & 2.6 & 1.0 & 1.0 \\
\hline & 600 & $\cdots$ & $\cdots$ & $\cdots$ & $\cdots$ & 196 & 73 & 21 & 5.1 & 1.0 & 1.0 \\
\hline & 700 & $\ldots$ & $\ldots$ & $\ldots$ & $\ldots$ & $\ldots$ & 160 & 45 & 8.4 & 1.0 & 1.0 \\
\hline
\end{tabular}

(d) Final $\mathrm{Al} / \mathrm{Si}$ values (Normalized to $\mathrm{CI}$ )

\begin{tabular}{|c|c|c|c|c|c|c|c|c|c|c|c|}
\hline \multirow[t]{7}{*}{$11 \mathrm{~km} \mathrm{~s}^{-1}$} & 100 & 1.0 & 1.0 & 1.0 & 1.0 & 1.0 & 1.0 & 1.0 & 1.0 & 1.0 & 1.0 \\
\hline & 200 & 1.0 & 1.0 & 1.0 & 1.0 & 1.0 & 1.0 & 1.0 & 1.0 & 1.0 & 1.0 \\
\hline & 300 & 1.1 & 1.1 & 1.1 & 1.0 & 1.0 & 1.0 & 1.0 & 1.0 & 1.0 & 1.0 \\
\hline & 400 & 1.3 & 1.3 & 1.3 & 1.2 & 1.1 & 1.1 & 1.0 & 1.0 & 1.0 & 1.0 \\
\hline & 500 & 1.5 & 1.5 & 1.4 & 1.3 & 1.2 & 1.1 & 1.0 & 1.0 & 1.0 & 1.0 \\
\hline & 600 & 2.1 & 2.0 & 1.9 & 1.7 & 1.5 & 1.3 & 1.1 & 1.0 & 1.0 & 1.0 \\
\hline & 700 & 2.6 & 2.5 & 2.4 & 2.1 & 1.8 & 1.5 & 1.2 & 1.0 & 1.0 & 1.0 \\
\hline \multirow[t]{4}{*}{$16 \mathrm{~km} \mathrm{~s}^{-1}$} & 100 & 1.1 & 1.1 & 1.1 & 1.1 & 1.0 & 1.0 & 1.0 & 1.0 & 1.0 & 1.0 \\
\hline & 200 & 3.8 & 3.6 & 3.2 & 2.6 & 2.0 & 1.5 & 1.2 & 1.0 & 1.0 & 1.0 \\
\hline & 300 & 21 & 20 & 16 & 11 & 7.0 & 4.1 & 2.3 & 1.3 & 1.0 & 1.0 \\
\hline & 400 & 109 & 99 & 76 & 49 & 26 & 11 & 4.8 & 2.0 & 1.0 & 1.0 \\
\hline
\end{tabular}


Table 3

(Continued)

\begin{tabular}{ccccccccccccc}
\hline \hline Entry Velocity & Size $(\mu \mathrm{m})$ & $\mathrm{ZA}=0^{\circ}$ & $10^{\circ}$ & $20^{\circ}$ & $30^{\circ}$ & $40^{\circ}$ & $50^{\circ}$ & $60^{\circ}$ & $70^{\circ}$ & $80^{\circ}$ & $90^{\circ}$ \\
\hline & 500 & 314 & 265 & 172 & 99 & 50 & 20 & 7.3 & 2.6 & 1.0 & 1.0 \\
& 600 & $\cdots$ & $\cdots$ & $\cdots$ & $\cdots$ & 257 & 76 & 21 & 5.1 & 1.0 & 1.0 \\
& 700 & $\cdots$ & $\cdots$ & $\cdots$ & $\cdots$ & $\cdots$ & 199 & 45 & 8.4 & 1.0 & 1.0 \\
\hline
\end{tabular}

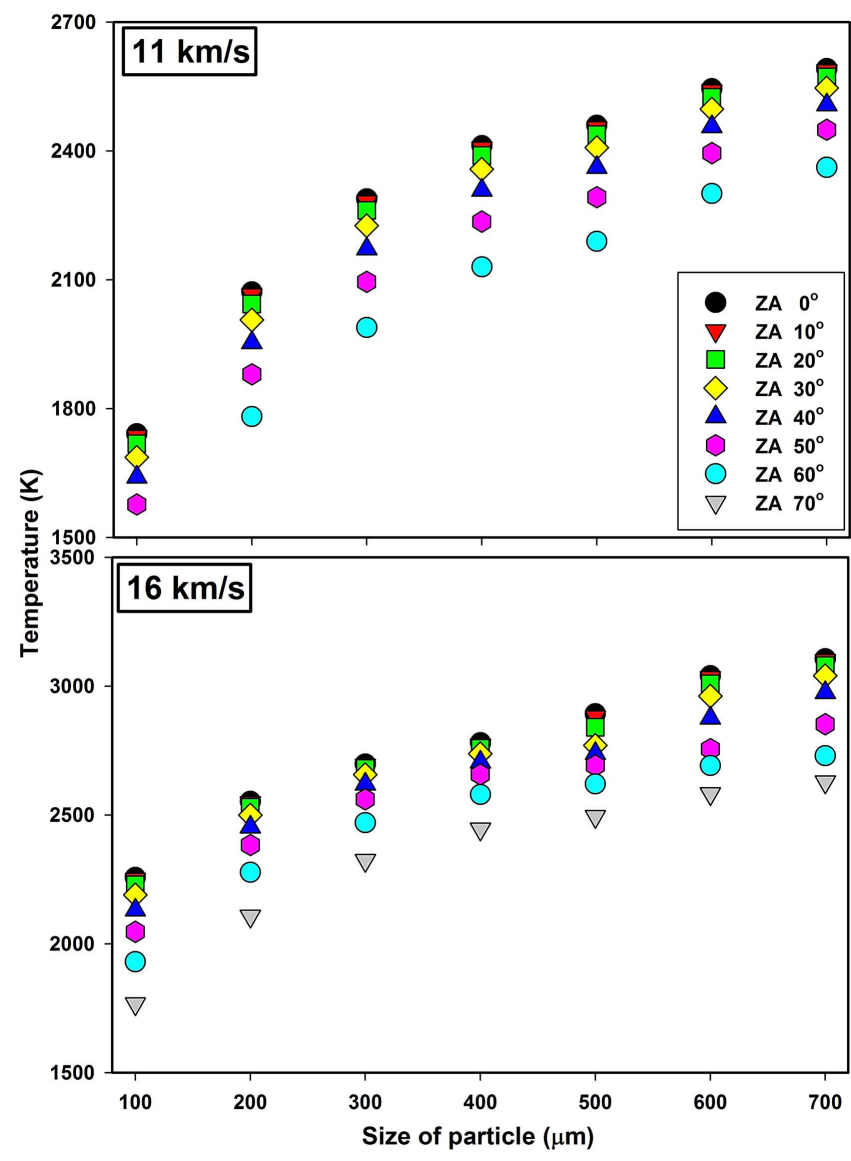

Figure 9. Distribution of temperature for various sizes $(100-700 \mu \mathrm{m})$ at various ZAs for entry velocities 11 and $16 \mathrm{~km} \mathrm{~s}^{-1}$. The temperature (K) experienced by particles entering at ZAs $\geqslant 70^{\circ}$ with entry velocity $11 \mathrm{~km} \mathrm{~s}^{-1}$ is below $750 \mathrm{~K}$, and hence is not visible in range plotted.

processes and which stages of deviation are relevant for attaining these particles' precursor compositions. The information provided by this study provides an understanding of the stoichiometry, chemical alteration from the initial composition, ablation, and mass-loss during atmospheric entry for different entry parameters such as size, entry velocity, and zenith angle. Here we have demonstrated that for an entry velocity of $11 \mathrm{~km} \mathrm{~s}^{-1}$, the major element chemical compositions are preserved for particle sizes $<400 \mu \mathrm{m}$, beyond which $\mathrm{FeO}$ largely ablates. The ablation is drastic for particles with an entry velocity of $16 \mathrm{~km} \mathrm{~s}^{-1}$, where particle elemental ratios vary largely and major elements get depleted, leaving behind refractory elements $\mathrm{Al}$ and $\mathrm{Ca}$. The model indicates that for an entry velocity of $11 \mathrm{~km} \mathrm{~s}^{-1}$, ZAs $30^{\circ}-60^{\circ}$ contribute to melted particles, while ZAs $70^{\circ}-90^{\circ}$ are dominated by unmelted particles. For particles with a velocity of $16 \mathrm{~km} \mathrm{~s}^{-1}$, the contribution of melted particles gets restricted to narrow ZAs due to large-scale ablation, and that for unmelted particles is restricted to ZAs $>80^{\circ}$. Overall, the survivability of the particles at low entry velocities with ZAs $30^{\circ}-90^{\circ}$ seems feasible and is estimated to be $\sim 20,000$ tons/annum.

This research was supported by the GEOSINKS, MOESPMN, and the PLANEX projects. The CABMOD model development is supported by the European Research Council (project 291332-CODITA). This is NIO's contribution No. 5958.

\section{REFERENCES}

Bohren, C. F., \& Huffman, D. R. 1983, Absorption and Scattering of Light by Small Particles (New York: Wiley-Interscience)

Brownlee, D., Tsou, P., Aléon, J., et al. 2006, Sci, 314, 1711

Brownlee, D. E. 2001, in Accretion of Extraterrestrial Matter Throughout Earth's History, ed. B. Peucker-Ehrenbrink \& B. Schmitz (New York: Kluwer/Plenum)

Brownlee, D. E. 2014, AREPS, 42, 179

Brownlee, D. E., Bates, B., \& Schramm, L. 1997, M\&PS, 32, 157

Carrillo-Sánchez, J. D., Plane, J. M. C., Feng, W., Nesvorný, D., \& Janches, D. 2015, GeoRL, 42, 6518

Cziczo, D. J., Thomson, D. S., \& Murphy, D. M. 2001, Sci, 291, 1772

Dermott, S. F., Jayaraman, S., Xu, Y. L., Gustafson, B. A. S., \& Liou, J. C. 1994, Natur, 369, 719

Erickson, J. E. 1968, JGR, 73, 3721

Flynn, G. J. 1989a, LPSC, 19, 673

Flynn, G. J. 1989b, Icar, 77, 287

Hashimoto, A. 1983, GeocJ, 17, 111

Hunten, D. M., Turco, R. P., \& Toon, O. B. 1980, JAtS, 37, 1342

Kessler, D. J. 1969, AIAAJ, 7, 2337

Kortenkamp, S. J., Dermott, S. F., Fogle, D., \& Grogan, K. 2001, in Accretion of Extraterrestrial Matter Throughout Earth's History, ed. B. Peucker-Ehrenbrink \& B. Schmitz (New York: Kluwer/Plenum)

Krot, A. N., Keil, K., Goodrich, C. A., Scott, E. R. D., \& Weisberg, M. K. 2003, in Classification of Meteorites. In Meteorites, Comets, and Planets. In Treatise on Geochemistry, Vol. 1, ed. A. M. Davis (Amsterdam: Elsevier)

Kurat, G., Koeberl, C., Presper, T., Brandstätter, F., \& Maurette, M. 1994, GeCoA, 58, 3879

Lal, D., \& Jull, A. T. J. 2002, APJ, 576, 1090

Lodders, K., \& Fegley, B., Jr. 1998, The Planetary Scientist's Companion (New York: Oxford Univ. Press)

Love, S. G., \& Brownlee, D. E. 1991, Icar, 89, 26

Love, S. G., \& Brownlee, D. E. 1993, Sci, 262, 550

Love, S. G., Joswiak, D. J., \& Brownlee, D. E. 1994, Icar, 111, 227

Mason, B. 1971, Handbook of Elemental Abundances of the Elements in Meteorites (Newark: Gordon and Breach)

Maurette, M., Jéhanno, C., Robin, E., \& Hammer, C. 1987, Natur, 328, 699

Nesvorný, D., Janches, D., Vokrouhlický, D., et al. 2011, ApJ, 743, 129

Nesvorný, D., Jenniskens, P., Levison, H. F., et al. 2010, ApJ, 713, 816

Peucker-Ehrenbrink, B., \& Ravizza, G. 2000, GeCoA, 64, 1965

Plane, J. M. C. 2012, Chem. Soc. Rev., 41, 6507

Prasad, M. S., Rudraswami, N. G., \& Panda, D. K. 2013, JGR, 118, 2381

Rudraswami, N. G., Prasad, M. S., Babu, E. V. S. S. K., et al. 2012, GeCoA, 99, 110

Rudraswami, N. G., Prasad, M. S., Dey, S., et al. 2015a, APJ, 814, 78

Rudraswami, N. G., Prasad, M. S., Plane, J. M. C., et al. 2014, GeCoA, 131, 247

Rudraswami, N. G., Shyam Prasad, M., Dey, S., et al. 2016a, APJ, 831, 197

Rudraswami, N. G., Shyam Prasad, M., Jones, R. H., \& Nagashima, K. 2016b, GeCoA, 194, 1

Rudraswami, N. G., Shyam Prasad, M., Nagashima, K., \& Jones, R. H. 2015b, GeCoA, 164, 53

Rudraswami, N. G., Ushikubo, T., Nakashima, D., \& Kita, N. T. 2011, GeCoA, 75,7596

Schaefer, L., \& Fegley, B. 2005, EMP, 95, 413 
Sears, D. W., \& Dodd, R. T. 1988, in Meteorites and the Early Solar System, ed. J. F. Kerridge \& M. S. Matthews (Tucson, AZ: Univ. Arizona Press) Taylor, S., Herzog, G. F., \& Delaney, J. S. 2007, M\&PS, 42, 223

Taylor, S., Lever, J. H., \& Harvey, R. P. 1998, Natur, 392, 899

Taylor, S., Lever, J. H., \& Harvey, R. P. 2000, M\&PS, 35, 651
Taylor, S., Matrajt, G., \& Guan, Y. 2012, M\&PS, 47, 550

Vondrak, T., Plane, J. M. C., Broadley, S., \& Janches, D. 2008, ACP, 8,7015

Yada, T., Nakamura, T., Noguchi, T., et al. 2005, GeCoA, 69, 5789

Yada, T., Nakamura, T., Takaoka, N., et al. 2004, EPS, 56, 67 